\title{
Structural Characterization of Iron Oxide Grown On 18\% Ni-Co-Mo-Ti Ferrous Base Alloy Aged Under Superheated Steam Atmosphere
}

\author{
Andréia de Souza Martins Cardoso ( $\square$ bra_afs@hotmail.com ) \\ Universidade Federal Fluminense https://orcid.org/0000-0003-4758-9396
}

Hugo Ribeiro da Igreja

Universidade Federal Fluminense

Pedro Soucasaux Pires Garcia

Universidade Federal Fluminense

Rodrigo Chales

Universidade Federal Fluminense

Juan Manuel Pardal

Universidade Federal Fluminense

\section{Sergio Souto Maior Tavares}

Universidade Federal Fluminense

\section{Maria Margareth Silva}

Instituto Tecnológico de Aeronáutica (ITA-DCTA)

\section{Andrea Paesano}

Universidade Estadual de Maringá (UEM)

\section{Luc Pichon}

Université de Poitiers

\section{Research Article}

Keywords: $18 \%$ Ni-Co-Mo-Ti Ferrous base alloys, Maraging steel, Hydrogen embrittlement, Characterization oxide layers

Posted Date: July 23rd, 2021

DOl: https://doi.org/10.21203/rs.3.rs-626449/v1

License: (c) (i) This work is licensed under a Creative Commons Attribution 4.0 International License.

Read Full License 


\section{Abstract}

$18 \% \mathrm{Ni}$-Co-Mo-Ti Ferrous base alloys are special materials, widely used in the industry of isotopic enrichment after specific annealing and aging thermal treatment. The desirable high mechanical properties can then be attained by adequate aging heat treatment, answering the structural materials specifications required by defense applications in aerospace and nuclear engineering. For instance, the isotopic enrichment, in rocket engine envelope application, when associated with high temperature and chemical residues like acidic solutions, can induce corrosion and hydrogen embrittlement in martensite structures. To limit these corrosion and hydrogen embrittlement phenomena, an adherent and protective layer of iron oxides can be grown on the material surface by using adequate atmosphere during the aging treatment. Due to its application in strategic areas, the characterization of these oxide layers in maraging steels is of importance as well as the understanding of their growth kinetics. For this purpose, several techniques, such as Optical Microscopy (OM), Scanning Electron Microscopy (SEM), Glow Discharge Optical Emission Spectroscopy (GDOES), Microabrasive wear testing, Hardness, Grazing Incidence X-ray Diffraction (GIXRD) and X-ray Photoelectron Spectroscopy (XPS), have been performed for chemical and structural characterization of the oxide films formed after vapor exposed thermal aging at $510^{\circ} \mathrm{C}$. The oxide layer consists mostly in two sub-layers composed by magnetite $\left(\mathrm{Fe}_{3} \mathrm{O}_{4}\right)$ and an external layer of hematite $\left(\mathrm{Fe}_{2} \mathrm{O}_{3}\right)$. A thick interface between the oxide layer and the bulk is enriched in $\mathrm{Ti}$ and $\mathrm{Mo}$, whereas the analyses of deep bulk material show an enriched area with $\mathrm{Ni}$ and $\mathrm{Co}$.

\section{Highlights}

- Several techniques were applied for Maraging steel layers characterization.

- A new approach by calotest, nanohardness and X-ray quantification were employed.

- Layers characterization was analyzed and discussed in agreement with literature.

- The layers distinction was satisfactorily evaluated.

\section{Introduction}

Maraging steels, basically Fe-Ni-Co-Ti alloys with low carbon content, are often used in the ultracentrifuge envelope,. Thus, their microstructural matrix consists in a relatively soft martensitic structure (BCC-body centered cubic) [1, 2] some research compare this structural with low tetragonality [3]. Nonetheless, these materials exhibit excellent mechanical properties at the aged condition due to precipitation hardening of intermetallic phases such as $\mathrm{Ni}_{3}(\mathrm{Ti}, \mathrm{Mo})$ and $\mathrm{Fe}_{2} \mathrm{Mo}[2,4]$. Besides, some previous works has shown that the nickel atoms in the $\mathrm{Ni}_{3} \mathrm{Ti}$ unit cell can be replaced by cobalt and iron atoms, while titanium atoms can be replaced by molybdenum atoms [3]. It is important to note that distortions could have been observed while performing high temperature aging, due to the formation of reverse austenite $\left(\mathrm{Fe}_{\mathrm{x}} \mathrm{Ni}\right)$. Therefore, the general formula for these precipitates would be $(\mathrm{Ni}, \mathrm{Fe}, \mathrm{Co})_{3}(\mathrm{Ti}, \mathrm{Mo})$ and their fraction of $\mathrm{Mo}$ and Ti would depend on the alloy composition. However, when adding cobalt to these alloys family, it's also possible to 
find Laves phase $\left(\mathrm{Fe}_{2} \mathrm{Mo}\right)$, which are responsible for the high hardness peak and softening resistance during thermal aging [5].

As depicted before, the great advantage of this steel family is the excellent formability in the solution annealed condition and the possibility to achieve a combination of good toughness with a high mechanical strength after aging. But despite these good properties, when subjected to hydrogen containing environment, the maraging steels are prone to embrittlement phenomenon, altering its mechanical behaviour and ultimately leading to brittle fracture [6-8]. The general mechanism of hydrogen embrittlement involves the adsorption and subsequent diffusion of atomic hydrogen into the bulk metal, reducing its ductility and fracture resistance [9]. The formation of atomic hydrogen on the surface of the steel when exposed to a gaseous hydrogen environment requires the dissociation of molecular hydrogen, and further details of this mechanisms could be found elsewhere $[9,10]$.

An oxide layer can be used as a protective barrier against hydrogen diffusion and uptake, and can withstand stress and corrosion phenomena commonly occuring during nuclear fission $[9,10]$. Such an oxide layer can be formed during thermal aging, while being exposed to a superheated water vapor atmosphere. So, studying the oxidation kinetics involving the alloying elements and estimating the layer composition is of primary importance. Various studies pointing out the Gibbs free energies of oxide formation $[11,12]$ lead to the conclusion that the oxide layer formation could be approximated by 3 different kinetic models: linear, parabolic and logarithmic. The model which will better describe the particular phenomenon will depend on the temperature and the alloy chemical composition. In this study, the model which better describes the oxidation process is logarithmic, with a quickinitial phase of the oxide growth followed by a decrease of the growth rate as fast as the thickness increased, indicating the protective effect $[5,13]$.

Malafaia and Shreir et al.[14] proposes the formation of three overlapping layers: the outermost, composed by hematite or iron oxide II $\left(\mathrm{Fe}_{2} \mathrm{O}_{3}\right.$ hexagonal compact is considered the highest state of iron oxidation, with almost 70 at.\% iron in its composition, while oxygen occupies the other 30 at.\%); an intermediate one corresponds to the magnetite oxide $\left(\mathrm{Fe}_{3} \mathrm{O}_{4}-\mathrm{CFC}\right)$ and the inner one by wustite ( $\mathrm{FeO}$ CFC) $[14,15]$. These three layers act together as a barrier to the progress of oxidation and also hinders the hydrogen uptake, thus playing a vital role in reducing hydrogen damage [16].

The growth mechanism of the oxide film was studied by Klein et al. [10,17], which in this case has been described as an outward migration of iron cations during the thermal oxidation of Fe-Ni-Co alloys, occurring in air, water steam and also carbon dioxide environment. Experimental results obtained by Auger electron spectroscopy and depth profile determination, SEM-XES analysis and X-ray diffraction supported these assumptions, but besides the fact that the oxide formation and cation migration were proved measuring their binding energies, they didn't quantify the oxide layer thicknesses.

On the other hand, Rezek et al. [10] studied the microstructure and mechanical behavior changes when producina an oxide laver in a 250 maraaina steel by high temperature heating in a water steam Loading [MathJax]/jax/output/CommonHTML/jax.js 
containing environment. The coating consisted in an innermost layer of austenitic phase and a magnetite $\mathrm{Fe}_{3} \mathrm{O}_{4}$ external layer. The results showed lower elongation and only a limited reduction in the measured hydrogen diffusion coefficient for the coated maraging when comparing with the bare steel. Despite that fact, the threshold stress in stress corrosion cracking (SCC) evaluation was significantly higher for the coated steel. This benefit is attributed to presence of the austenitic sub-layer.

Another interesting study, promoted by Greyling et al. [18], investigated the oxidation kinetics of a grade 300 maraging steel heated in air at temperatures ranging from 300 to $600^{\circ} \mathrm{C}$. The authors used Auger electron spectroscopy in conjunction with argon ion sputtering, and noted that, a thin gold layer sputtered onto the surface before oxidation resulted to a change in the kinetics from limited-thickness to approximately parabolic growth at temperatures below $480^{\circ} \mathrm{C}$. The limited-thickness oxide growth is described in terms of space-charge effects, as outlined by the theory of Formhold. The insulating properties of a thin mixed spinel oxide present at the metaloxide interface is critical in bringing about the space charge in the oxide.

Recently Florez et al. [19] showed that oxide characterization is important for embrittlement environments because surface treatments lead to inducing a superficial layer that in some cases could be protective. An oxide layer was generated under different atmospheres during the thermal aging treatment of different maraging grades. Afterwards, this layer was microstructural and mechanically characterized by advanced characterization techniques and the results showed that the oxide layer was made up of several compounds like: $\mathrm{TiO}_{2}, \mathrm{MoO}_{3}, \mathrm{a}-\mathrm{Fe}_{2} \mathrm{O}_{3}$, and $\mathrm{CoFe}_{2} \mathrm{O}_{4}$. Furthermore, a nickel-rich austenitic phase at the interphase was mainly made up cobalt ions $\left(\mathrm{Co}^{2+}\right)$, instead of iron ions $\left(\mathrm{Fe}^{2+}\right)$, within the spinel lattice [19].

So, the purpose of the present study is to perform a thorough characterization, of the structure and composition of the iron oxide layer grown on a maraging steel 350 class after thermal aging in a superheated steam media. Thus, the characterization methods employed in this study consisted of OM, SEM coupled with EDS, Mosbauer, GDOES, Microabrasive wear testing, Hardness, GIXRD and XPS. The results obtained in this work are of great relevance, since maraging 350 class are commonly employed in reactors or high energy fusion housing, both environments which are considered highly aggressive to martensitic materials regarding its low resistance to stress corrosion cracking. The formation of an oxide protective layer during thermal aging can enhance the material's performance in those applications without further increases in the total manufacturing cost and time.

\section{Materials And Methods}

The chemical composition of the maraging 350 steel employed in this study is presented in Table 1. 
Table 1

Chemical composition (wt.\%) of maraging steel grade 350 .

\begin{tabular}{|lllllllllll|}
\hline $\mathbf{N i}$ & Co & Mo & Ti & C & S & P & Al & Cr & Mn & Fe \\
\hline 17,65 & 11,65 & 4,69 & 1,44 & $\Downarrow 0,1$ & $\Downarrow 0,1$ & $\otimes 0,1$ & $\Downarrow 0,1$ & $\otimes 0,1$ & $\Downarrow 0,1$ & Balance \\
\hline
\end{tabular}

Twenty samples $(20 \mathrm{~mm} \times 20 \mathrm{~mm} \times 2 \mathrm{~mm}$ ) were prepared by precision cutting. All of them were then annealing treated (ST) at $910^{\circ} \mathrm{C}$ for $1 \mathrm{~h}$, in a vacuum oven with controlled atmosphere with argon. The samples were sand the 200 to 1200 microns. Then, ten samples were aged (ST + A) at $510^{\circ} \mathrm{C}$ for $6 \mathrm{~h}$ in a Lindberg MPH type 12-1416 Steam Homo Pit Furnace with controlled atmosphere, according to the methodology presented by COESTER et al [20].

Cross section samples were prepared by low speed cutting to be characterized by the several techniques described beforehand. In order to perform the optical microcopy (OM) characterization, the ST and STA cross section treated samples were carefully embedded, grinded and then polished by metallographic conventional procedure, followed by chemical attack with both Potassium Metabisulfite and Marble regents. OM was then performed in a model Axio Imager 2 Carl Zeissin, whereas the Scanning Electron Microscopy (SEM) took place in a model Vega 3 Tescan, operated at $20 \mathrm{kV}$ in a secondary electron (SE) mode in both chemical attacks. Microelementar analyses by EDS (dispersive energy spectroscopy) were performed along the sample's depth, from the the oxide layer to the bulk. Finally, Mössbauer spectroscopy was performed using "converting electron" (CEMS) geometry. Thus, it was possible to study the most

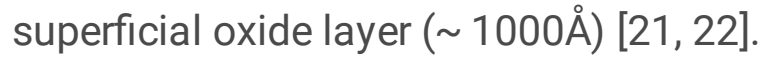

GDOES test was performed in a Horiba Jobin-Yvon GD-Profiler ${ }^{\circledR}$, using a Pure Argon (800 Pa) R.F. plasma with applied power of 20W on $2 \mathrm{~mm}$ diameter electrode. Light intensities emitted by desexcitation of sputtered atoms/ions were separated in a polychromator enabling simultaneous analysis of the elements of concern during the analysis duration. Quantification of element concentration was calculated thanks to previous calibrations curves based on references samples. The sputtering rate was determined on each sample by measuring the produced crater, enabling to determine the concentration profile. Each sample was analysed several times, stopping the analysis sputtering at different depths to determine the sputtering rate of each layer.

The ST and STA samples were also characterized by micro-abrasive wear tests, which were performed on a small scale abrasive wear test instrument from Anton Paar. The test was conducted on a oxidized sample with a flat surface, whose dimensions are $25 \times 15 \mathrm{~mm}^{2}$, using a $25.4 \mathrm{~mm}$ diameter steel sphere with a normal force $\mathrm{N}$ of $0.2 \mathrm{~N}$ with a duration of $5 \mathrm{~s}$. The peripheral speed of the sphere was equal to 6.65 $\mathrm{mm} / \mathrm{s}$, and the abrasive solution consisted in diamond paste from with an average particle size of $1 / 4 \mu \mathrm{m}$. The results obtained were corroborated by Rupetsov and Minchev [23].

The analyzed thicknesses were calculated by $h=x y / D$ [23-25], where $x$ is the width of the halo; $d$ is the inner diameter of the groove $(y=d-x)$ and $D$ the diameter of the ball. After the wear testing, a Vickers hardness profile was raised along the layers of the hubcap, from the oxidized layer to the substrate, using Loading [MathJax]/jax/output/CommonHTML/jax.js sed two penetrator, first a Square Base Pyramidal penetrator 
and second the Berkovich penetrator, with regular triangular base pyramidal geometry. Eighteen measurements in cross section from surface to the bulk were obtained with a $2.5 \mathrm{gf} \mathrm{load} \mathrm{maintained}$ during 10 seconds, while on the surface it was used $0.01 \mathrm{gf}$ and for 15 seconds. Micro hardness HV test were also operated with load of $25 \mathrm{gf}$ and time of 10 seconds in triplicate in cross section and on surface. The complementar ultrasonic contact impedance test was conducted in triplicate using the MIC-205 31991 - 7747 digital durometer, with a load of $5 \mathrm{kgf}$ and the MIC 10 digital display, in triplicate, on surface.

The technique of GIXRD was used in order to allow the structural characterization of the most superficial oxide layer $[16,18,20]$. The GIXRD technique was performed with the Rigaku equipment, model Ultima IV, equipped with CuKa source $(\lambda=1.5406 \AA)$. The equipment operated with an angular step of $0.02^{\circ}$, under voltage of $40 \mathrm{kV}$ and $30 \mathrm{~mA}$ current. The critical angle for this case, to avoid the total external reflection of the X-ray beam, was $0.32^{\circ}$ [26]. Consequently, the grazing incidences were chosen as follow $0.5^{\circ}, 1^{\circ}$, $1.5^{\circ}, 2^{\circ}, 3^{\circ}$ and $5^{\circ}$, in continuous scan mode from $20^{\circ}$ to $90^{\circ}$, leading to $0,09 \mu \mathrm{m}$ until $8,7 \mu \mathrm{m}$ probed depths [24]. Rigaku PDXL was used for the identification and estimated quantification of volumetric fraction of the present phases [23]. The computational calculation of the mass attenuation coefficient of the mixture were based on NIST Standard (NBSIR 87-3597 [27]) with the relative weights for each compound quantified by de GIXRD.

Another technique used to evaluate the chemical composition on the surface of the oxidized sample was the X-ray Photoelectron Spectroscopy (XPS), using the Kratos model AXIS ULTRA DLD. XPS uses monochromatic Al-Ka radiation and fixed transmission mode analyzer (80 and $40 \mathrm{eV}$ ). The spectra were referenced from line $\mathrm{C} 1 \mathrm{~s}$ (binding energy, $\mathrm{BE}=284.5 \mathrm{eV}$ ) of the hydrocarbon. Samples were analysed with $400 \mu \mathrm{m}$ diameter beams with $300 \mathrm{~W}$. Survey spectra and high-resolution spectra were acquired using pass energies of $300 \mathrm{eV}$ and $50 \mathrm{eV}$, respectively. Power step size $0.100 \mathrm{eV}$ and number of power steps 401 . The acquisition and quantification of the data were performed with the Kratos software, while the spectra were analyzed by peak adjustment followed by Gaussian second order and second derivative, taking into account the baseline according to the Shirley method in the origin software.

\section{Results And Discussion}

The microstructure of class 350 maraging steel obtained by OM analyses is shown in Figs. 1 and 2 for the ST and STA samples respectively, allowing the observation of the surface characteristics in the ST condition, and the presence of lath martensite. The STA condition leads to an oxide microlayer with $2 \pm$ $0,3 \mu \mathrm{m}$ formed at the samples surface.

The SEM-EDS analysis, presented in Fig. 3 and Table 2, indicated the segregation of $\mathrm{Ni}, \mathrm{Co}, \mathrm{Mo}$ and $\mathrm{Ti}$ from the base steel to the external sub-layer causing local enrichment near the layer boundary [28]. However, the semi-quantitative analysis by EDS presented in Table 2 indicates that the chemical composition of the bulk material was not affected by the heat treatment. In this sense, Klein et al.[17] ctinulatod that olomontal nvidation in ctoam oxidized Fe-Ni-Co alloys can be explained by the iron Loading [MathJax]/jax/output/CommonHTML/jax.js 
diffusion mechanism. Since Ni and Co can't be oxidized in the process, they serve as inert markers and their position indicates the interface between base material and oxidized layer.

Table 2: Cross Section and Surface top semi quantitative point chemical analyses of EDS in Wt\%

\begin{tabular}{|lllllll|}
\hline \multicolumn{2}{|l}{ Cross Section Analyses } & \multicolumn{1}{l|}{ No } & & & & \\
\hline Point Analyses & $\mathrm{Fe}$ & 0 & $\mathrm{Ni}$ & $\mathrm{Co}$ & $\mathrm{Mo}$ & $\mathrm{Ti}$ \\
\hline 1 & 68.0 & 27.0 & 0 & 2.5 & 2.4 & 0.0 \\
\hline 2 & 60.6 & 27.4 & 4 & 3.4 & 3.5 & 1.1 \\
\hline 3 & 50.5 & 25.6 & 7.8 & 6.8 & 7.5 & 1.8 \\
\hline 4 & 49.8 & 23.3 & 8.7 & 8.0 & 8.1 & 2.2 \\
\hline 5 & 35.7 & 6.0 & 31.7 & 19.15 & 5.5 & 1.8 \\
\hline 6 & 32.2 & 7.1 & 32.2 & 20.66 & 6.1 & 1.8 \\
\hline 7 & 48.3 & 3,2 & 26.0 & 15.78 & 5.3 & 1.4 \\
\hline 8 & 58.5 & 1.9 & 19.7 & 13.02 & 5.49 & 1.41 \\
\hline Surface Analyses & & & & & \\
\hline Point Analyses & $\mathrm{Fe}$ & 0 & $\mathrm{Ni}$ & $\mathrm{Co}$ & $\mathrm{Mo}$ & $\mathrm{Ti}$ \\
\hline 1 & 65.6 & 31.7 & 0.9 & 1.1 & 0.5 & 0.1 \\
\hline
\end{tabular}

The SEM images also allowed the measurement of the oxidized layer thickness, as observed in Fig. 3. It is important to note the existence of two distinct regions, one external and one internal sub-layer, with a total thickness of approximately $2 \mu \mathrm{m}$. The innermost layer presents diffusion behavior of the different alloying elements added to 350-grade maraging steel. These elements were involved in the formation of the protective oxide layer during thermal aging under superheated water vapor atmosphere [16]. In Fig. 5 and Table 2 the bulk material region near the boundary with the oxide layer, it is formed an intermediate layer, rich in $\mathrm{Ni}$ and $\mathrm{Co}$ in points 3 until 5, and point 6 and 7 showed a leading to austenite stabilization because Ni was increasing $[21,22,29]$.

However, in Fig. 5 and Table 2, it is shown that the outermost layer formation follows a semi-qualitative stoichiometry of approximately $66 \% \mathrm{Wt}$ of $\mathrm{Fe}$ to $32 \% \mathrm{Wt}$ for $\mathrm{O}$ with traces of $\mathrm{Mo}, \mathrm{Ni}$ and $\mathrm{Co}$, indicating that the outermost formation is composed of hematite $\left(\mathrm{Fe}_{2} \mathrm{O}_{3}\right)[14,15]$. This result was corroborated by Mössbauer spectroscopy on CEMS that confirms the presence of the sextet referring to the formation of hematite oxide, as presented in Fig. 6.

On the other hand, the Microabrasive wear testing characterization results shown in Fig. 7 presented the formation of two layers formed on the substrate. Following the V RUPETSOV and R MINCHEV method 
after $5 \mathrm{~s}$ of microabrasive wear testing, the outermost layer thickness measures approximately $1,5 \pm 0,2$ $\mu \mathrm{m}$ and the innermost layer one is about $0,7 \pm 0,1 \mu \mathrm{m}[30]$.

Hardness nano measurements were carried out at the spherical cap, at different depths, allowing to access the hardness profile as indicated by Figs. 7 and 8 with tree diferent layers, in top of surface until $0.8 \mu \mathrm{m}$ the hardness is $1600 \mathrm{HV}$, the second layer is in $0.8 \mu \mathrm{m}$ until $1.5 \mu \mathrm{m}$ the hardness is $2000 \mathrm{HV}$ following with a gradual decrease in $1.5 \mu \mathrm{m}$ until $1.8 \mu \mathrm{m}$ with $1500 \mathrm{HV}$, than in the bulk depleted in iron and rich in nickel from $2.0 \mu \mathrm{m}$ until 2,6 $\mu \mathrm{m}$ with $900 \mathrm{HV}$, and 2,6 $\mu \mathrm{m}$ is the bulk with $750 \mathrm{HV}$, average. The analysis of these regions means hardness values from the surface to bulk, presenting high standard deviation. The growth kinetics of oxides is non-linear, this behaviour is due to the fact that the atomic diffusion is not unidirectional, resulting in a non-planar boundary surface between substratemagnetite and magnetite-hematite, which leads to the high observed deviations. So, the initial measurements on the samples surface can be a hardness peak or a valley that characterizes the growth of the iron oxide layer under study. This high deviations indicates the existence of sub-layer interfaces, corroborating that the material presents a double layer formation, originated from the growth of the protective oxide during the heat treatment in a steam furnace.

Furthermore, the hardness measurements, accessed by nano indentation into the cap region, made it possible to observe average values for each separate layer: the white layer next to the substrate presented $900 \pm 200 \mathrm{HV}$, the intermediate layer $2090 \pm 380 \mathrm{HV}$, the region near the boundary $1640 \pm 250 \mathrm{HV}$ and the substrate $785 \pm 120 \mathrm{HV}$. Nano-, micro- and impedance hardness results obtained on the surface and in the bulk aregathered in Table 3. In this sense, the impedance hardness measurements at the bulk region, in the ST condition, resulted in $442 \pm 6 \mathrm{HV}$ and $768 \pm 6 \mathrm{HV}$ for the STA condition. The oxidized surface presented a value of $830 \pm 310 \mathrm{HV}$. It is clear that the surface measurements with nano and impedance techniques have a high deviation due to the porous characteristic of the outermost layer and these are techniques sensitive to heterogeneous surface formation $[1,5]$.

Table 3

Hardness measures with different techniques - HV

\begin{tabular}{|llll|}
\hline Conditions & Nano & Micro & Contact ultrasonic impedance \\
\hline ST - bulk & $399 \pm 17$ & $445 \pm 25$ & $442 \pm 6$ \\
\hline STA - bulk & $772 \pm 20$ & $998 \pm 47$ & $768 \pm 6$ \\
\hline STA - top surface & $790 \pm 535$ & $772 \pm 20$ & $826,04 \pm 309$ \\
\hline
\end{tabular}

The element concentration profiles determined by GDOES are presented in Fig. 9. An oxide layer of about $1 \mu \mathrm{m}$ is clearly visible, with oxygen content decreasing form 80 at.\% to about 60 at.\% and iron content increasing between 20 and 40 at.\%. Ni, Co and Mo were not observed in this layer before $\sim 0.7 \mu \mathrm{m}$, likely because of the rough interface between the top iron oxide and the underneath oxide. Below this iron oxide layer, the oxygen gradient is quickly decreasing till depth of about $2 \mu \mathrm{m}$ whereas iron is still increasing till 
increasing till a maximum at $1.5 \mu \mathrm{m}$ before decreasing back to their bulk value.. These profiles are confirming the growth mechanism of the oxide, based on iron diffusion toward the surface to build the Fe2O3 oxide, some inward diffusion of oxygen and then the relative enrichment in alloying elements (Ni, $\mathrm{Co}, \mathrm{Mo})$ in the intermediate oxidized depth due to the lower Fe content. [18, 31].

In order to obtain structural information about the surface layers, grazing incidence X-ray diffraction (GIXRD) was operated with different incidence angles to allow different penetration depths of the radiation. Figure 10 shows the diffractograms generated for incidence angles of $0.5,1^{\circ}, 1.5^{\circ}, 2^{\circ}, 3^{\circ}$ and $5^{\circ}$ $[5,32,33]$, and Table 4presents the quantification data acquired by Rietveld method.

Table 4

Phases proportions obtained by Rietveld quantification method.

\begin{tabular}{|lllll|}
\hline $\mathbf{G .} \mathbf{A}^{\circ}$ & $\mathrm{Fe}_{2} \mathrm{O}_{3}$ & $\mathrm{Fe}_{3} \mathrm{O}_{4}$ & $\mathbf{Y}$ & $\mathbf{a}$ \\
\hline $0,5^{\circ}$ & $65,5 \%$ & $25,0 \%$ & $8,8 \%$ & $0,7 \%$ \\
\hline $1^{\circ}$ & $58,7 \%$ & $29,1 \%$ & $7,3 \%$ & $4,9 \%$ \\
\hline $1,5^{\circ}$ & $57,6 \%$ & $27,3 \%$ & $12,5 \%$ & $2,6 \%$ \\
\hline $2^{\circ}$ & $48,8 \%$ & $34,8 \%$ & $11,7 \%$ & $4,6 \%$ \\
\hline $3^{\circ}$ & $45,8 \%$ & $31,8 \%$ & $15,2 \%$ & $7,2 \%$ \\
\hline $5^{\circ}$ & $41,0 \%$ & $22,6 \%$ & $20,5 \%$ & $15,9 \%$ \\
\hline
\end{tabular}

Using incident angles typically lower than $1.5^{\circ}$, the signal from the substrate can be minimized, increasing the intensity of the diffraction peaks associated with the crystalline structures next to the surface. Some researchers [24] argue that it is possible to obtain a more reliable quantification for the oxide layer using the relationship of photon interaction with the substrate thickness at some angles, especially in the case of phases with low volumetric fraction, as for example the intermetallic, binary and inorganic compounds formed at the substrate interface [2].

At the referred layer, the main crystalline phase is hematite, followed by magnetite. For the incident angles between $0.5^{\circ}$ and $1.5^{\circ}$, an average hematite / magnetite ratio of $60 \%$ per $40 \%$ is maintained, which was also reported by other studies $[14,15]$. However, for angles higher than $2^{\circ}$, the magnetite fraction increased, and at $3^{\circ}$ the results presented also martensite peaks (charac teristic peaks of a' $\mathrm{Fe}(110)$, (200) and (211)). From these results, it could be presumed that there was a formation of an external hematite layer and an internal magnetite sub layer. According to Rezek et al. [10], X-ray diffraction results indicated a higher percentage of hematite, inferring that a third oxide layer could be formed [2].

In an approach to calculate the penetration depth, it was used the method described by Birkholz [34], considering a sample with infinite thickness and the thickness of the upper layer that accounts for (1-1/ $(\rho)=63 \%$ of the meacured intencitv Wlith the thickness and phase quantification of each GIXRD Loading [MathJax]/jax/output/CommonHTML/jax.js 
diffractogram, an estimative of phase quantification for each thickness was done. Considering that only the depth penetration of the incident beam changes with the increase of a, the Eq. (2) was proposed to perform the layer phase quantification.

$$
\frac{q_{n}}{\left(t_{n}-t_{n-1}\right) b}=\left(Q_{n}-\sum_{i=1}^{n-1} \frac{Q_{i} t_{i}}{t_{n}}\right)\left(\frac{t_{n}}{t_{n}-t_{n-1}}\right)
$$

Where:

Q: Phase quantification measured in all volume by GIXRD

t: Analyzed film thickness

b: The surface area of analysis

q: Layer Quantification

$\mathrm{n}=0,5^{\circ} \longrightarrow 5^{\circ}$

Figure 11 show the estimated results of the layer thickness on the material based on the Eq. 2 . The result with $5^{\circ}$ incidence angle shows a penetration depth of $3,5 \mu \mathrm{m}$, and the highest quantity of $a$ and $\gamma$ phases. This is in good correlation with the previously observed $2 \mu \mathrm{m}$ thick oxide layer. Concerning the oxide layer, a first surface layer mainly composed of hematite is confirmed within the first $1 \mu \mathrm{m}$ layer. Below, at the interface with the bulk, the magnetite is presenting a peak of proportion.

Graat et al. [35] made the analysis through the Fe $2 p$ spectrum for a sample of pure Fe and obtained the peaks with binding energy of $706.8 \mathrm{eV}$ for $\mathrm{Fe}^{0}$ and $709.8 \mathrm{eV}$ and $711.2 \mathrm{eV}$ for the $\mathrm{Fe}^{2+}$ and $\mathrm{Fe}^{3+}$ cations (Table 5). Satellite peaks present with a higher energy level, less intensity and always to the left of the main peaks with energy of $722.8 \mathrm{eV}$ and $724.3 \mathrm{eV}$ for $\mathrm{Fe}^{2+}$ and $\mathrm{Fe}^{3+}$ cations [32]. The doublets or multiplets that reveal the formation of satellite peaks in the spectrum of the main ions $\left(\mathrm{Fe}^{2+}\right.$ and $\left.\mathrm{Fe}^{3+}\right)$. These peaks are due to the movement of electrons from the $3 \mathrm{~d}$ orbital to the empty $4 \mathrm{~s}$ orbital during the ejection of the electron photon from the $2 p$ nucleus [35]. In analyses performed in Table 5the peaks summarize that binding energies used for XPS technique. 
Table 5

Binding energies used for XPS analysis for the Fe $2 p$ spectrum [33].

\begin{tabular}{|c|c|c|}
\hline \multirow[t]{2}{*}{ Espectrum Compound Fe 2p } & \multicolumn{2}{|c|}{ Peaks of Binding Energies (eV) } \\
\hline & Peak $1\left(2 p_{3 / 2}\right)$ & Peak $2\left(2 p_{1 / 2}\right)$ \\
\hline $\mathrm{Fe}_{2} \mathrm{O}_{3}$ & $709,8-710,9$ & 724,3 \\
\hline $\mathrm{Fe}^{3+}$ satellite & $\sim 719,0$ & $\sim 733,0$ \\
\hline $\mathrm{Fe}_{3} \mathrm{O}_{4}$ & $709,0-710,4$ & 722,0 \\
\hline $\mathrm{Fe}^{2+}$ satellite & $\sim 715,0$ & $\sim 730,0$ \\
\hline $\mathrm{FeO}$ & $708,4-709,4$ & N/A \\
\hline $\mathrm{Fe}^{0}$ & $706,7-707,0$ & 719,8 \\
\hline Fe $2 p$ & 710,9 & 724,5 \\
\hline FEOOH & 711,8 & - \\
\hline
\end{tabular}

In Figure 12 the XPS spectrum on the surface of the ST sample can be interpreted as the sum of the following iron components $\left(\mathrm{Fe}^{0}, \mathrm{Fe}^{2+}, \mathrm{Fe}^{3+}\right.$ and $\left.\mathrm{Fe}_{2} \mathrm{O}_{3}\right)$ in the $2 \mathrm{p}$ spectrum and their respective satellite peaks. For the STA condition, $\mathrm{Fe}$ in hematite was identified at 709 to $710 \mathrm{eV}$ at $2 \mathrm{p}_{3 / 2}$ and 722 to $724 \mathrm{eV}$ at $2 p_{1 / 2}$; $F$ in magnetite is found at $728 \mathrm{eV}$ for the $2 p_{1 / 2}$ peak and in the range of approximately 713 to 718 $\mathrm{eV}$ for the $2 \mathrm{p}_{3 / 2}$ Peak. It is also observed the formation of satellite peaks to $2 \mathrm{p}_{3 / 2} \mathrm{Fe}^{3+}$ at $714.5 \mathrm{eV}$, to $2 p_{1 / 2} \mathrm{Fe}^{2+}$ at $725 \mathrm{eV}$ and to $2 p_{3 / 2} \mathrm{Fe}^{2+}$ at $716 \mathrm{eV}$. The $2 \mathrm{p}_{3 / 2} \mathrm{Fe}^{-}$in $\mathrm{FeO}$ is also found at $709.5 \mathrm{eV}$. In Figure 10 , it can be seen that the analysis of the zero point (near the bulk-STA) at approximately $715 \mathrm{eV}$ and 730 $\mathrm{eV}$ shows low presence of magnetite in the STA condition, as well as the peaks at $706.5 \mathrm{eV}$ and $720 \mathrm{eV}$ show the high presence of metallic Fe for the ST condition according [21, 33].

In Fig. 12 the XPS spectrum on the surface of the ST sample can be interpreted as the sum of the following iron components $\left(\mathrm{Fe}^{0}, \mathrm{Fe}^{2+}, \mathrm{Fe}^{3+}\right.$ and $\left.\mathrm{Fe}_{2} \mathrm{O}_{3}\right)$ in the $2 \mathrm{p}$ spectrum and their respective satellite peaks. For the STA condition, $\mathrm{Fe}$ in hematite was identified at 709 to $710 \mathrm{eV}$ at $2 \mathrm{p}_{3 / 2}$ and 722 to $724 \mathrm{eV}$ at $2 p_{1 / 2}$; Fe in magnetite is found at $728 \mathrm{eV}$ for the $2 p_{1 / 2}$ peak and in the range of approximately 713 to 718 $\mathrm{eV}$ for the $2 \mathrm{p}_{3 / 2}$ Peak. It is also observed the formation of satellite peaks to $2 \mathrm{p}_{3 / 2} \mathrm{Fe}^{3+}$ at $714.5 \mathrm{eV}$, to $2 \mathrm{p}_{1 / 2} \mathrm{Fe}^{2+}$ at $725 \mathrm{eV}$ and to $2 \mathrm{p}_{3 / 2} \mathrm{Fe}^{2+}$ at $716 \mathrm{eV}$. The $2 \mathrm{p}_{3 / 2} \mathrm{Fe}^{-}$in $\mathrm{FeO}$ is also found at $709.5 \mathrm{eV}$. In Fig. 10, it can be seen that the analysis of the zero point (near the bulk-STA) at approximately $715 \mathrm{eV}$ and $730 \mathrm{eV}$ shows low presence of magnetite in the STA condition, as well as the peaks at $706.5 \mathrm{eV}$ and $720 \mathrm{eV}$ show the high presence of metallic Fe for the ST condition according [21, 33].

The ST top in XPS analysis showed $41 \%$ of oxide composed of $\mathrm{Fe}_{2} \mathrm{O}_{3}$ in $709,96 \mathrm{eV}$ and $723,27 \mathrm{eV}, 27 \% \mathrm{Fe}$ Loading [MathJax]/jax/output/CommonHTML/jax.js \% FeO in 707,65 eV, and 16\% other components. The top of 
STA formation of oxide composed of $63 \% \mathrm{Fe}_{2} \mathrm{O}_{3}$ in $709,96 \mathrm{eV}$ and $723,27 \mathrm{eV}$ and $37 \%$ of mixture of $\mathrm{Fe}_{3} \mathrm{O}_{4}$, $\mathrm{FeO}, \mathrm{FeOOH}, \mathrm{Fe}^{2+}, \mathrm{Fe}^{3+}$ and others is observed in 715,21 707,65, 711,58 eV. However, this analysis technique still needs to be improved, in Fig. 10 shows a movement of the peaks with the layer analysis, showing that the ratio of oxides formed changes with the depth, however the hematite and magnetite peaks divide the energy range very close, making the analysis difficult.

According to microabrasive wear and hardness analyzes, the layers have two characteristic thickness of approximately $1.08 \mu \mathrm{m}$ and $0.84 \mu \mathrm{m}$, resulting in a $1.92 \mu \mathrm{m}$ thick oxide layer. Therefore, since the scanning of the spectra was carried out up to $1.8 \mu \mathrm{m}$, it was not possible to analyze the relative increase of magnetite and iron oxide in the deeper layers. However, it was noticed a decrease in the $\mathrm{Fe}^{+}$satellites peaks, which accompany the hematite phase, even though no peaks referring to magnetite were observed. It is also important to note that hematite was the main oxide composing all analyzed layers, showing a higher mass fraction at the surface, which decreased towards the center of the analyzed layer. This behavior was corroborated by XRD and GIXRD results and by the diffusion of iron and oxygen observed by GDOS technique. In brief, all presented techniques showed the formation of a triple oxide layer, composed at its surface majorly by hematite (Mossbauer), followed by a mixture of hematite and magnetite. Near the material's bulk, it is also present a thin line with wustite and cobalt containing oxides, which leads to iron depletion and cobalt and nickel enrichment, favoring austenite stabilization and diffusion hardening at the matrix next the oxide layer.

\section{Conclusion}

The following conclusions could be drawn from the present work on the structural characterization of the iron oxide obtained on $18 \% \mathrm{Ni}$ (350) maraging steel treated in a superheated vapor steam furnace:

The optical microscopy and scanning electron microscopy analyses pointed out the presence of lath martensite at both conditions (ST and STA). Regardless, the STA sample treated in a water steam environment presented a $2,0 \pm 0,3 \mu \mathrm{m}$ thick oxide microlayer on its surface.

The energy dispersive spectroscopy (EDS) evidenced distinct surface regions from the bulk to the top surface: a nickel-rich region with iron impoverishment is covered by 2 sub-layers of iron oxides. At the sample surface, the outermost layer presents a semi-qualitative stoichiometry of approximately $66 \% \mathrm{wt}$ of $\mathrm{Fe}$ to $32 \%$ wt for $\mathrm{O}$, with only $\mathrm{Mo}, \mathrm{Ni}$ and $\mathrm{Co}$ traces, indicating that the outermost oxide is composed of hematite $\left(\mathrm{Fe}_{2} \mathrm{O}_{3}\right)$. This result was confirmed by Mössbauer spectroscopy with the sextet formation.

Using Microabrasive wear testing characterization it was possible to corroborate the formation of the two layers on the substrate and to measure the thickness of the outermost layer to approximately $1,5 \pm 0,2$ $\mu \mathrm{m}$, while the internal layer was $0,7 \pm 0,1 \mu \mathrm{m}$ thick.

The hardness measurements by nano indentation into the cap region produced by Microabrasive wear testing confirms the formation of a double layer, as well as an interface between these layers and the Loading [MathJax]/jax/output/CommonHTML/jax.js or each region studied were of $900 \pm 200 \mathrm{HV}$ for the white 
layer next to the substrate, while $2090 \pm 380 \mathrm{HV}$ for the intermediate oxide layer, $1640 \pm 250 \mathrm{HV}$ for the region near the bulk interface and $785 \pm 120 \mathrm{HV}$ for the substrate itself. Conventional hardness measurementresulted in $442 \pm 6 \mathrm{HV}$ for the ST matrix, $768 \pm 6 \mathrm{HV}$ for the STA matrix, and finally $830+/-310 \mathrm{HV}$ at the oxide layer surface.

The grazing incidence on X-ray diffraction analysis confirmed the presence of hematite and magnetite. Angles between $0.5^{\circ}$ and $1.5^{\circ}$, corresponding to the lower probed depths, evidenced the hematite formation in the top oxide, while angles higher than $2^{\circ}$ led to the magnetite peaks.

In the XPS peak deconvolution analysis it was detected the interaction of Fe with oxygen at the top until the nearest region of the bulk $(1,8 \mu \mathrm{m})$, using sputtering for depth analysis. On the other hand, the outer layers presented the formation of iron oxides composed by $63 \% \mathrm{Fe}_{2} \mathrm{O}_{3}$ and a mixture of $\mathrm{Fe}_{3} \mathrm{O}_{4}, \mathrm{FeO}$, $\mathrm{FeOOH}, \mathrm{Fe}^{2+}, \mathrm{Fe}^{3+}$ and other residuals. When analyzing the surface region, up to $1 \mu \mathrm{m}$ deep, it is noted the major presence of hematite (between 60 and 70\%), however this technique needs to be improved.

All correlated techniques showed that the oxide coating consists of a double layer, formed from the surface of the iron-depleted substrate by reverse diffusion and oxygen reduction. The substrate close to the layer is significantly richer in Nickel, also with a higher Co and Mo content, which leads to the formation of stable austenite. The interlayer has a mixture of oxides that consists mainly in a certain ration of hematite and magnetite. The amount of hematite increases towards the surface, followed by a reduction in the magnetite, which may indicate hematite formation in its outermost layer.

\section{Declarations}

\section{Acknowledgments}

1. Pró-Defesa IV - "High Mechanical Resistance Materials for Strategic Applications".

2. French Government program "Investissements d'Avenir" (LABEX INTERACTIFS, reference ANR-11LABX-0017-01 and EUR INTREE, reference ANR-18-EURE-0010).
a. Funding - Not Applicable
b. Conflicts of interest/Competing interests - Not Applicable
c. Availability of data and material - Not Applicable
d. Code availability - Not Applicable
e. Ethics approval - Not Applicable
f. Consent to participate - Not Applicable

g. Consent for publication - The authors declare that they have no known competing financial interests or Loading [MathJax]/jax/output/CommonHTML/jax.js ared to influence the work reported in this paper 
h. Authors' contributions - Andréia de Souza Martins Cardoso - Performed the tests and characterizations; Hugo Ribeiro da Igreja - Treated XRD and calo test results; Pedro Soucasaux Pires Garcia - Prepared and corrected the text; Rodrigo Chales - Prepared and corrected the text; Juan Manuel Pardal - Correlate Abstract and Introduction text and Reference; Sérgio Souto Maior Tavares - Correlate results and conclusions; Maria Margareth da Silva - Treated XPS test results; Andrea Paesano - Treated Mössbauer test results; Luc Pichon - Treated GDOS test results

\section{References}

1. Vasudevan VK, Kim SJ, Wayman CM (1990) Precipitation reactions and strengthening behavior in 18 Wt Pct nickel maraging steels. Metall Trans A, Phys Metall Mater Sci. https://doi.org/10.1007/BF02646061

2. Viswanathan UK, Dey GK, Asundi MK (1993) Precipitation hardening in 350 grade maraging steel. Metall Trans A. https://doi.org/10.1007/BF02646522

3. Nunes GCS, Sarvezuk PWC, Biondo V, et al (2015) Structural and magnetic characterization of martensitic Maraging-350 steel. J Alloys Compd. https://doi.org/10.1016/j.jallcom.2015.06.008

4. MAGNÉE, A; DRPIER, J.M; DUMONT, J; COUTSOURADIS, D; HABRAKEM L (1974) Cobalt Monograph Series

5. Vicente A de A, Brandi SD, Padilha AF (2015) EFEITO DO TEOR DE MOLIBDÊNIO NAS CURVAS DE ENDURECIMENTO POR PRECIPITAÇÃO E NA RESISTÊNCIA À OXIDAÇÃO A ALTAS TEMPERATURAS DE AÇOS MARAGING DE ULTRA ALTA RESISTÊNCIA MECÂNICA. Tecnol em Metal Mater e Mineração. https://doi.org/10.4322/2176-1523.0781

6. Pound B. (2000) The effect of aging on hydrogen trapping in precipitation-hardened alloys. Corros Sci 42:1941-1956. https://doi.org/10.1016/S0010-938X(00)00036-6

7. Tsay L, Lu H, Chen $C$ (2008) The effect of grain size and aging on hydrogen embrittlement of a maraging steel. Corros Sci 50:2506-2511. https://doi.org/https://doi.org/10.1016/j.corsci.2008.06.044

8. Tsay LW, Chi MY, Wu YF, et al (2006) Hydrogen embrittlement susceptibility and permeability of two ultra-high strength steels. Corros Sci. https://doi.org/10.1016/j.corsci.2005.05.042

9. Louthan MR (2008) Hydrogen embrittlement of metals: A primer for the failure analyst. J. Fail. Anal. Prev.

10. Rezek J, Klein IE, Yahalom J (1997) Structure and corrosion resistance of oxides grown on maraging steel in steam at elevated temperatures. Appl Surf Sci. https://doi.org/10.1016/S0169-4332(96)00587-9

11. Birks N, Meier GH, Pettit FS (1987) High-Temperature Corrosion Resistance. JOM. 
12. Schütze M (2003) Corrosion Books: Introduction to High Temperature Oxidation and Corrosion. By: A.S. Khanna - Materials and Corrosion 5/2003. Mater Corros. https://doi.org/10.1002/maco.200390081

13. Gentil V (2006) Corrosão, $4^{\mathrm{a}}$. LTC

14. Malafaia AM de S (2013) Oxidação cíclica em alta temperatura de ligas ferrosas fundidas de baixo custo. Universidade de São Paulo

15. Shreir LL, Jarman RA, Bursten GT (1994) Corrosion Metal - Environment Reactions

16. Li X, Chen L, Liu H, et al (2019) Atom doping in a-Fe2O3 thin films to prevent hydrogen permeation. Int J Hydrogen Energy. https://doi.org/10.1016/j.jhydene.2018.11.181

17. Klein IE, Yaniv AE, Sharon J (1981) The oxidation mechanism of Fe-Ni-Co alloys. Oxid Met. https://doi.org/10.1007/BF00603746

18. Greyling CJ, Kotzé IA, Viljoen PE (1990) The kinetics of oxide film growth on Maraging steel as described by space-charge effects. Surf Interface Anal. https://doi.org/10.1002/sia.740160161

19. Florez MAC, Fargas Ribas G, Rovira JJR, et al (2021) Characterization Study of an Oxide Film Layer Produced under C02/Steam Atmospheres on Two Different Maraging Steel Grades. Metals (Basel) 11:746. https://doi.org/10.3390/met11050746

20. Coester E, Krapf H, Pfistermeister M, et al (1977) Method for forming an anticorrosive oxide layer on steels

21. Mallinson CF, Tardio S, Yates PM, et al (2015) XPS Examination of the Oxide Layer Formed on Kovar Following Pre-Oxidation. Surf Sci Spectra 22:58-70. https://doi.org/10.1116/11.20150301

22. dos Santos LPM, Béreš M, de Castro MO, et al (2020) Kinetics of Reverted Austenite in 18 wt.\% Ni Grade 300 Maraging Steel: An In-Situ Synchrotron X-Ray Diffraction and Texture Study. JOM. https://doi.org/10.1007/s11837-020-04254-w

23. Rupetsov V, Minchev R (2016) Experimental Calo Tester for the Coating Thickness Measurement. XV Int Sci Conf

24. Henke BL, Gullikson EM, Davis JC (1993) X-ray interactions: Photoabsorption, scattering, transmission, and reflection at $\mathrm{E}=50-30,000 \mathrm{eV}, \mathrm{Z}=1-92$. At Data Nucl Data Tables. https://doi.org/10.1006/adnd.1993.1013

25. Leake J (2007) Thin film analysis by X-ray scattering. Mater Charact. https://doi.org/10.1016/j.matchar.2006.04.026 
26. Cai Y, Pan Y, Xue J, Su G (2009) Surficial phase-identification and structural profiles from weathered natural pyrites: A grazing-incidence X-ray diffraction study. Appl Surf Sci.

https://doi.org/10.1016/j.apsusc.2008.10.080

27. Berger M, Hubbell J, Seltzer S, et al (2010) XCOM: Photon Cross Sections Database (NIST)

28. Yerokhin AL, Nie X, Leyland A, Matthews A (2000) Characterisation of oxide films produced by plasma electrolytic oxidation of a Ti-6Al-4V alloy. Surf Coatings Technol. https://doi.org/10.1016/S02578972(00)00719-2

29. Gomes da Silva MJ, Cardoso JL, Carvalho DS, et al (2019) The effect of prior austenite grain size on hydrogen embrittlement of Co-containing 18Ni 300 maraging steel. Int J Hydrogen Energy. https://doi.org/10.1016/j.ijhydene.2019.05.074

30. Lohmann ILP, Sarvezuk PWC, Ferreira RF, et al (2019) Maraging-300: a structural and hyperfine study of steel aging. Hyperfine Interact 240:27. https://doi.org/10.1007/s10751-019-1566-y

31. Yates PM, Mallinson CF, Mallinson PM, et al (2017) An Investigation into the Nature of the Oxide Layer Formed on Kovar (Fe-29Ni-17Co) Wires Following Oxidation in Air at 700 and $800{ }^{\circ} \mathrm{C}$. Oxid Met. https://doi.org/10.1007/s11085-017-9772-y

32. Wilburn DR, Bassett WA (1978) Hydrostatic compression of iron and related compounds: an overview. Am Mineral

33. Moulder JF, Stickle WF, Sobol PE, Bomben KD (1992) Handbook of X-ray photoelectron spectroscopy: a reference book of standard spectra for identification and interpretation of XPS data

34. Birkholz M (2006) Thin Film Analysis by X-Ray Scattering

35. Graat PCJ, Somers MAJ, Böttger A (1995) Generalization of the tougaard method for inelasticbackground estimation in electron spectroscopy: Incorporation of a depth-dependent inelastic mean free path. Surf Interface Anal 23:44-49. https://doi.org/10.1002/sia.740230107

\section{Figures}



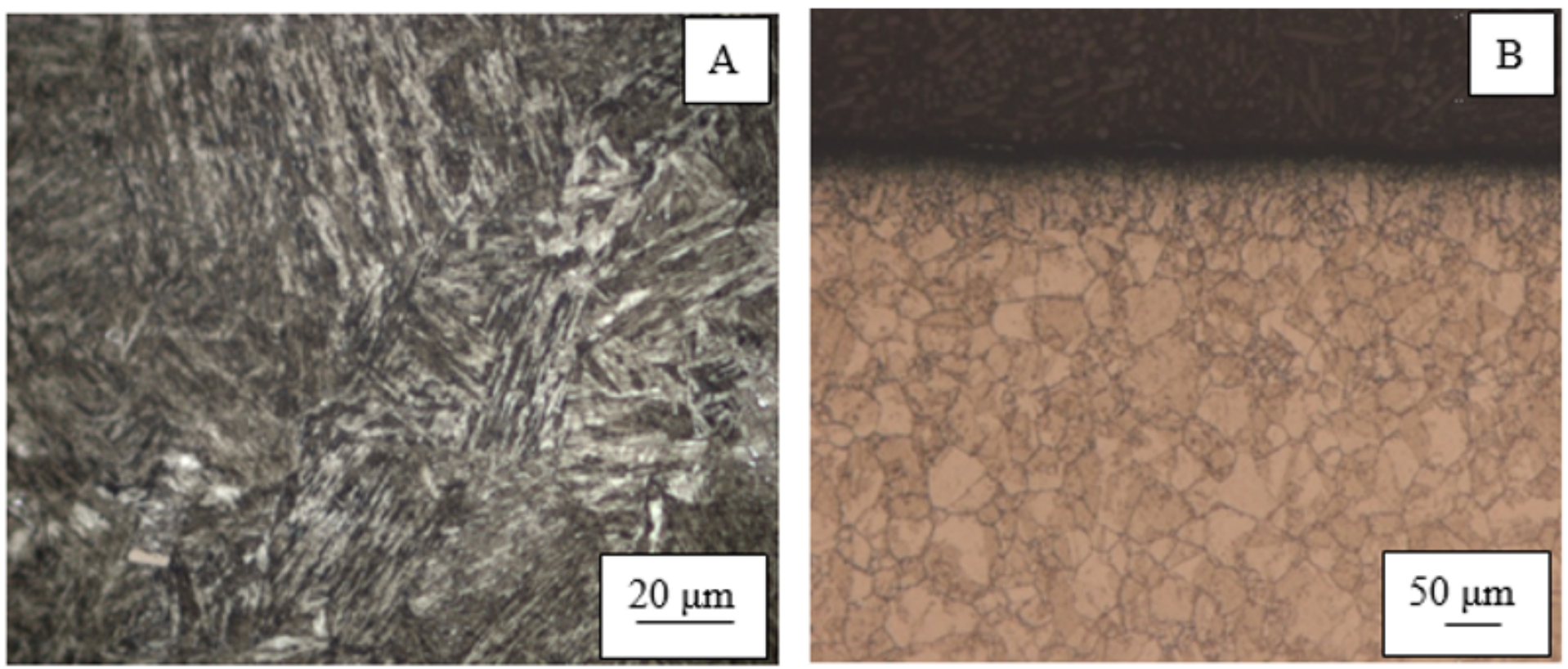

\section{Figure 1}

Bulk matrix view after Marble attack (A) and cross section view after Potassium Metabisulfite attack by scrub (B) - ST sample.
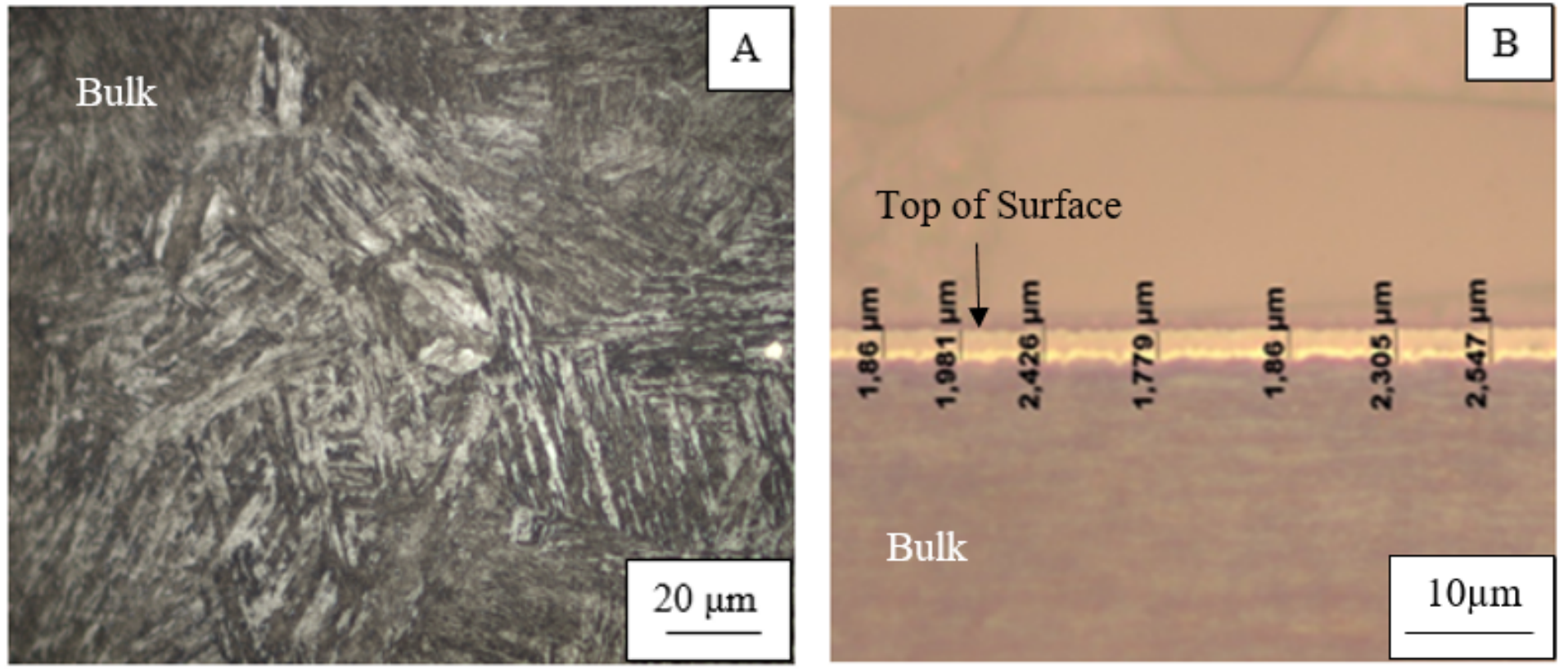

\section{Figure 2}

Bulk matrix view after Marble attack $(A)$ and cross section view after electrochemical attack Potassium metabisulfite by electric current (B) showing the top of surface (white) and bulk (grey) - STA sample. 


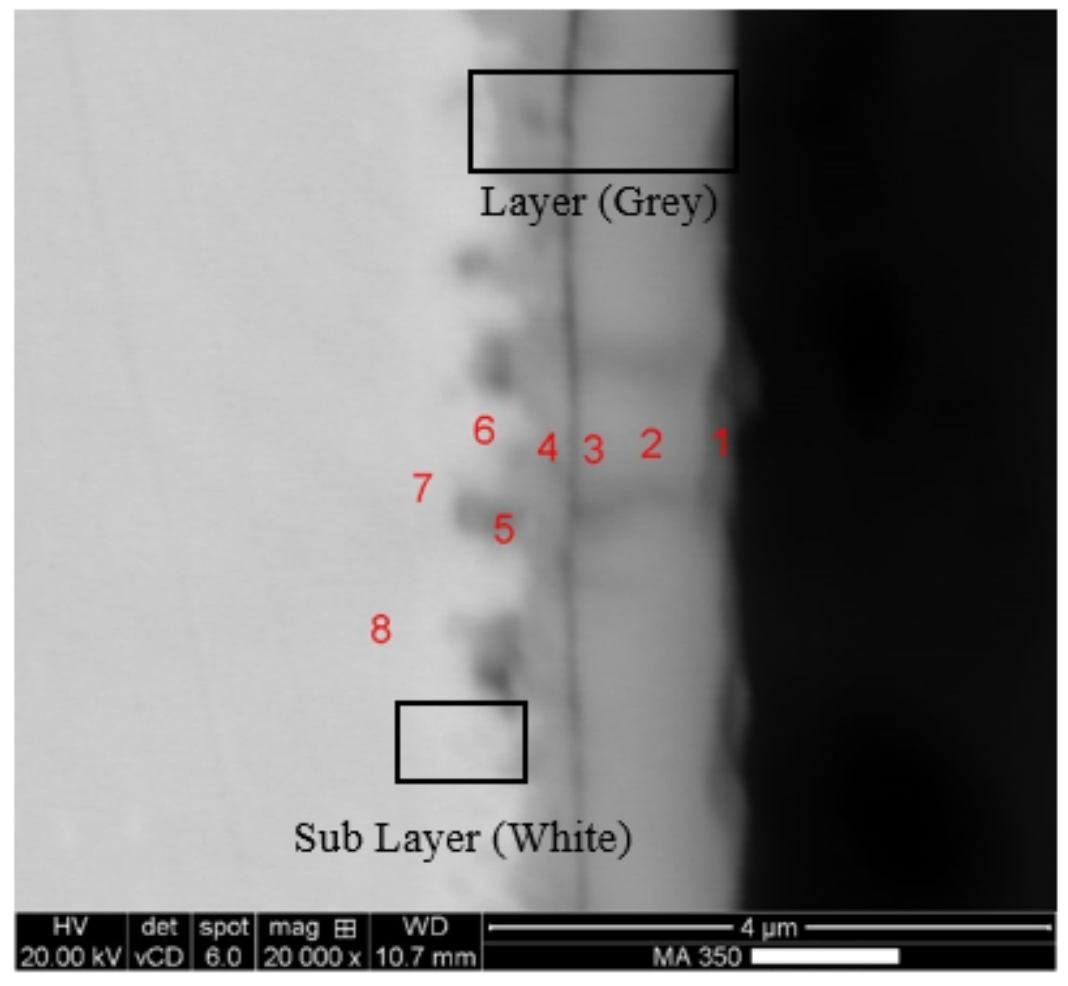

\section{Figure 3}

Metallographic section with indication of microanalyse points.

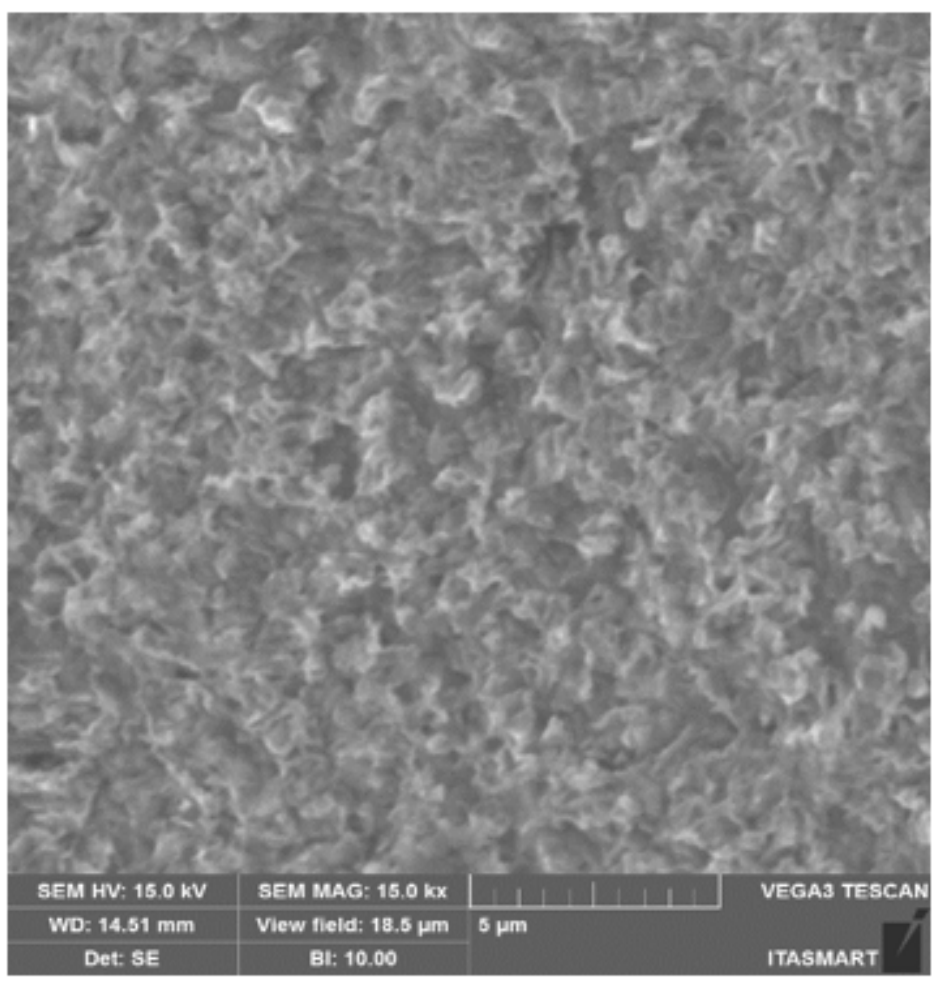

\section{Figure 4}

MEV on the samble surface oxide formation. Loading [MathJax]/jax/output/CommonHTML/jax.js 


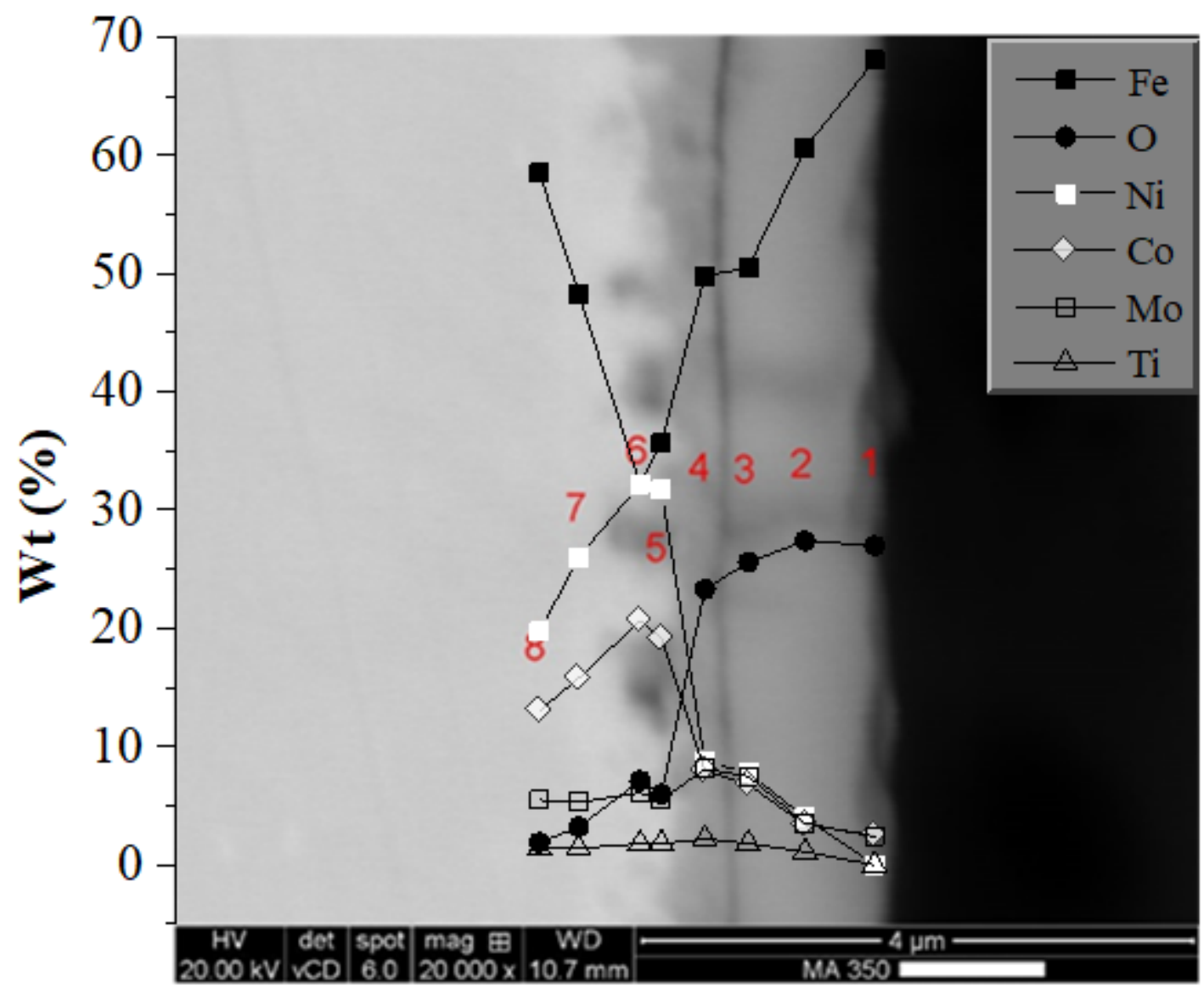

Figure 5

Cross Section Chemical Analyses by EDS

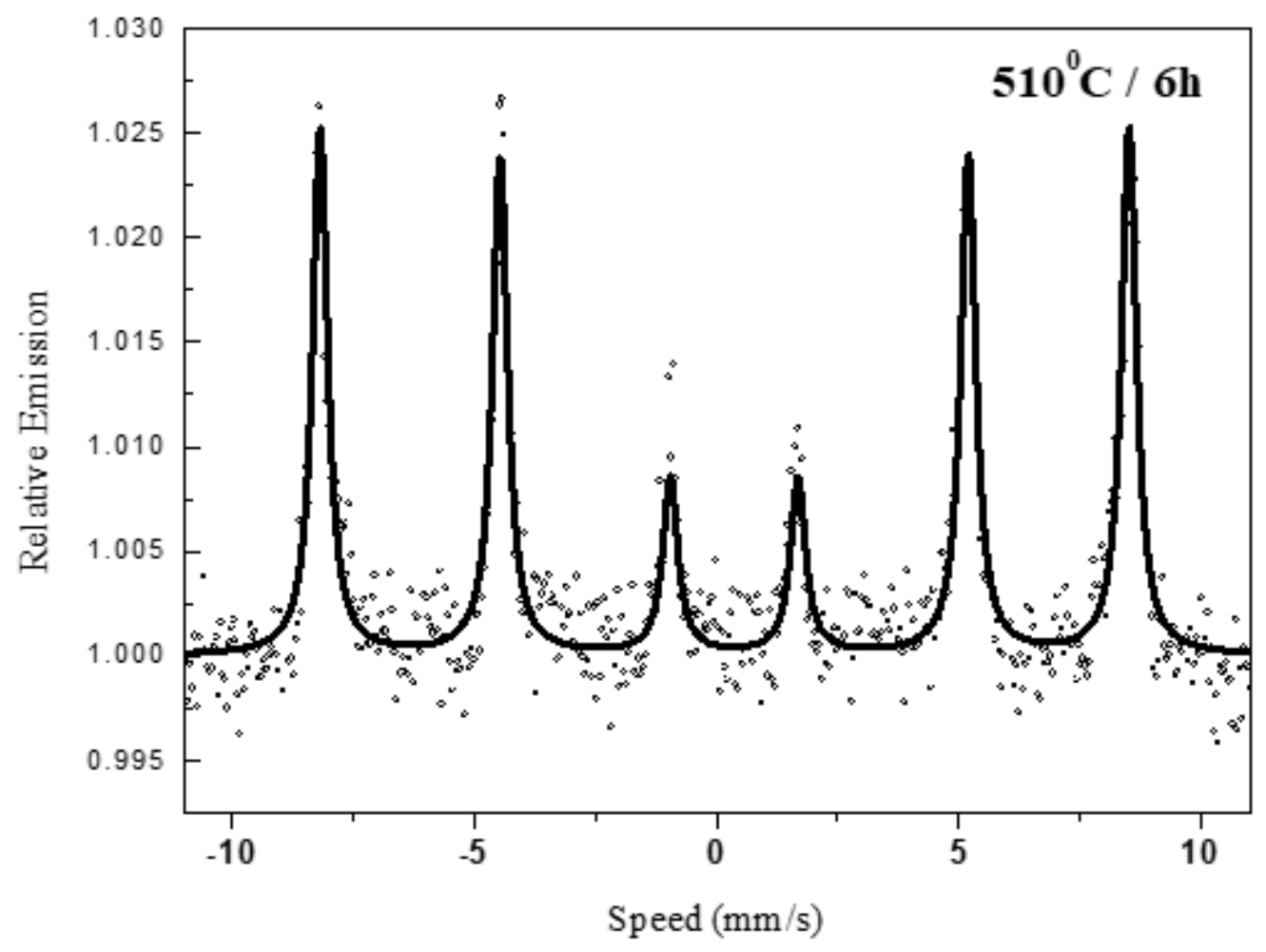

Loading [MathJax]/jax/output/CommonHTML/jax.js 


\section{Figure 6}

Mössbauer spectroscopy on CEMS technique that shows hematite formation in the outermost layer of the aged condition.

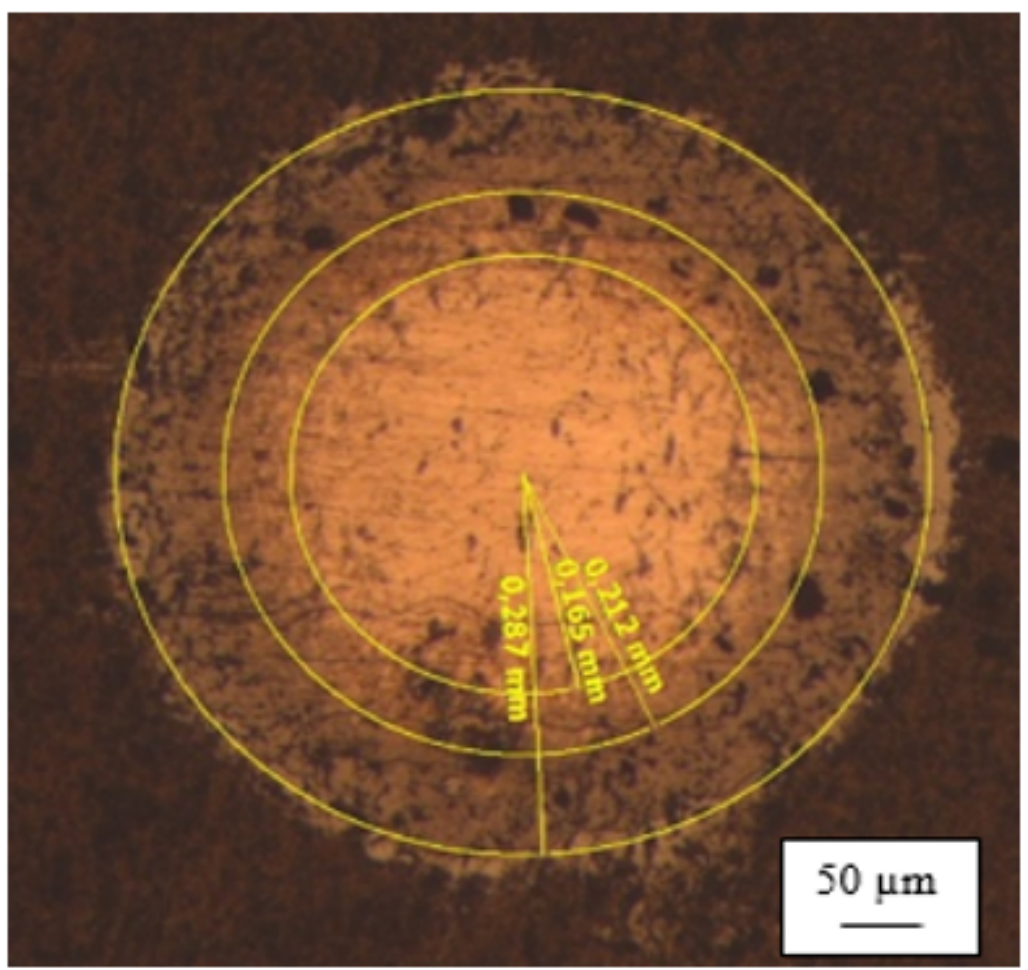

\section{Figure 7}

Image of the spherical cap formed after a 5-second Microabrasive wear testing. 


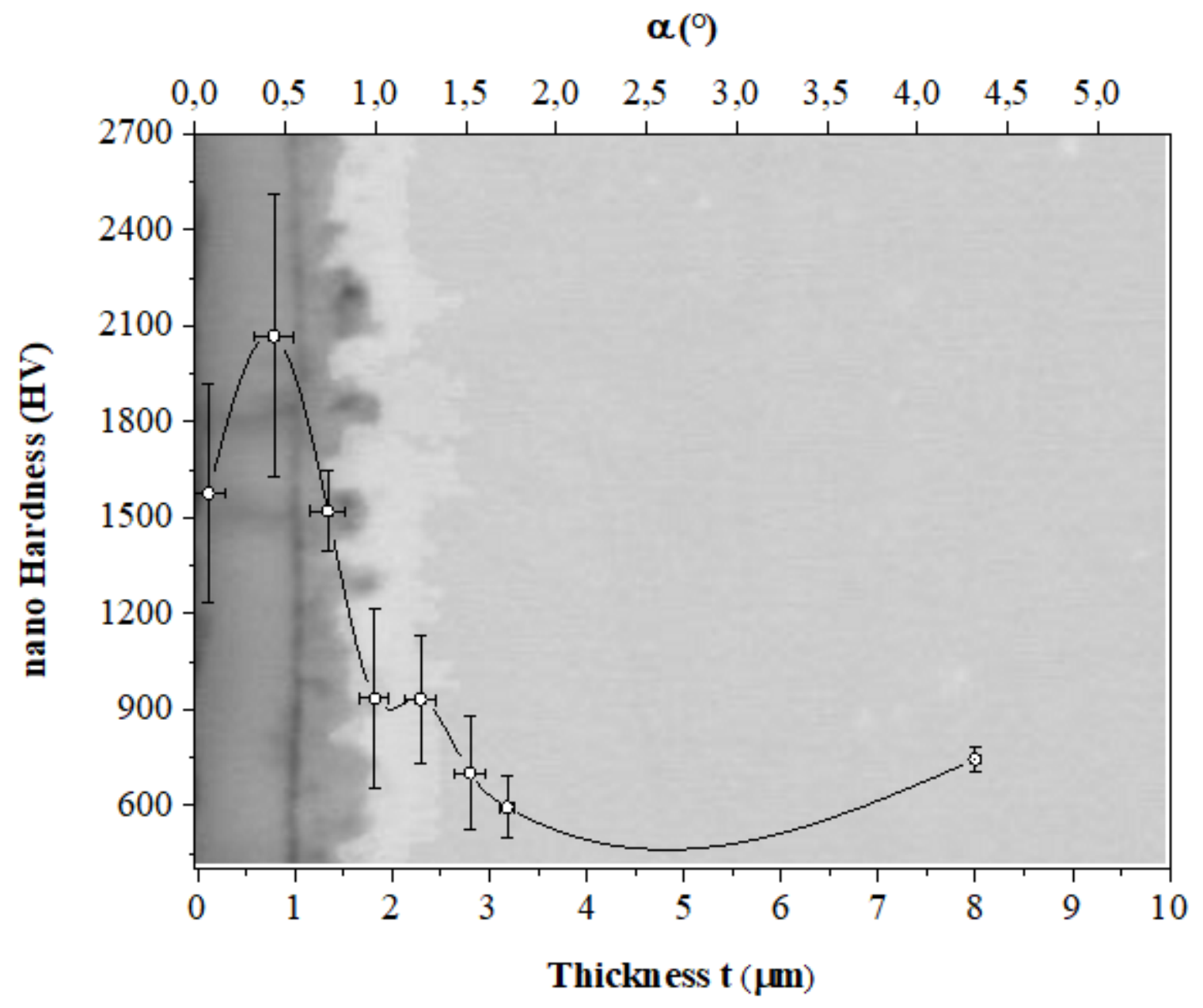

Figure 8

Hardness measurements along the cap of the STA sample. 


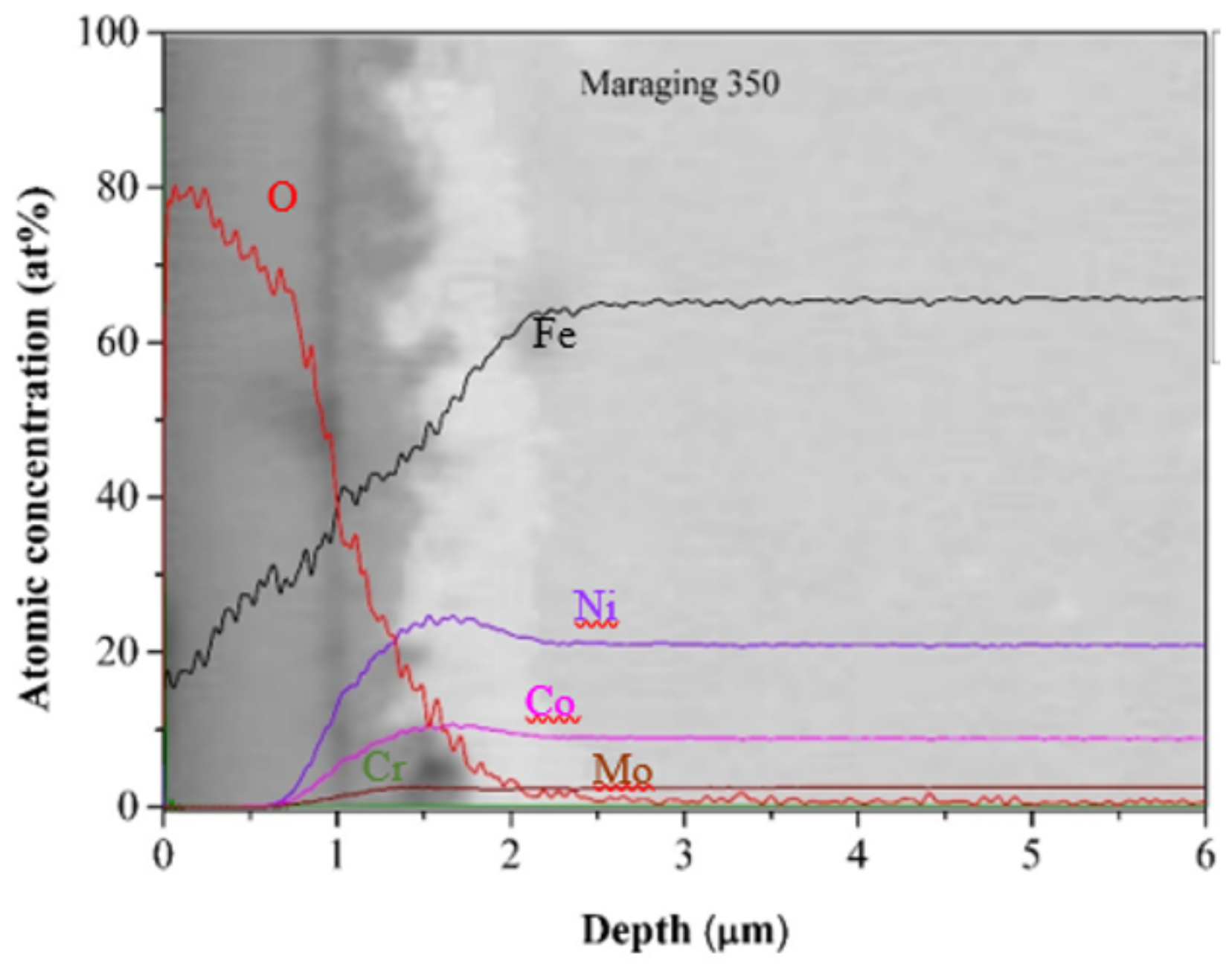

Figure 9

GDOS analysis of the main elements of the Fe $18 \% \mathrm{Ni}$ alloy. 


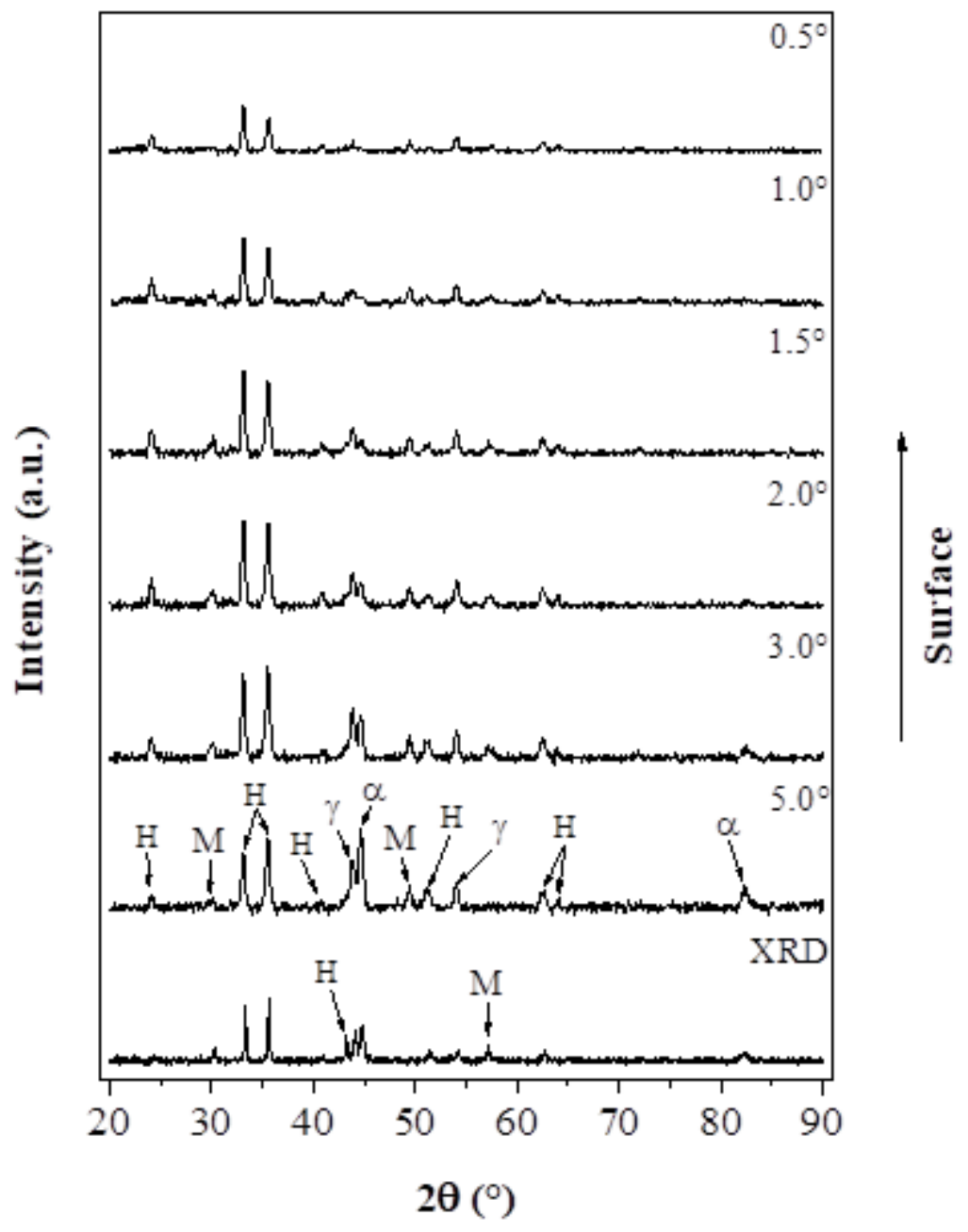

Figure 10

Diffractograms XRD Bragg-Brentano and GIXRD generated with incidence angles of $0.5^{\circ}, 1^{\circ}, 1.5^{\circ}, 2^{\circ}, 3^{\circ}$ and $5^{\circ}$. 


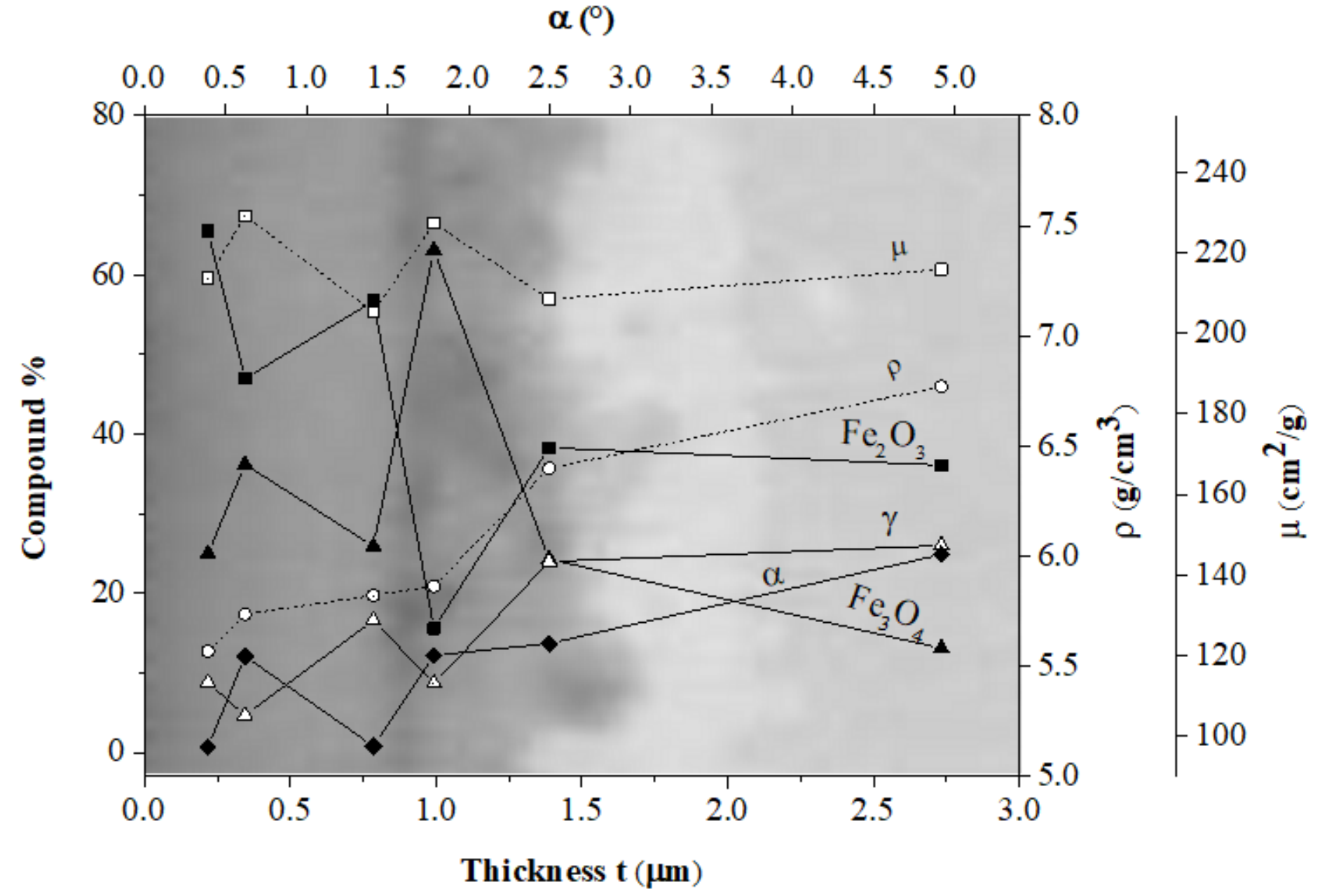

Figure 11

Evolution of the phases proportions with depth obtained from the GIXRD diffractograms generated from the angles of incidence equal to $0.5^{\circ}, 1^{\circ}, 1.5^{\circ}, 2^{\circ}, 3^{\circ}$ and $5^{\circ}$. 


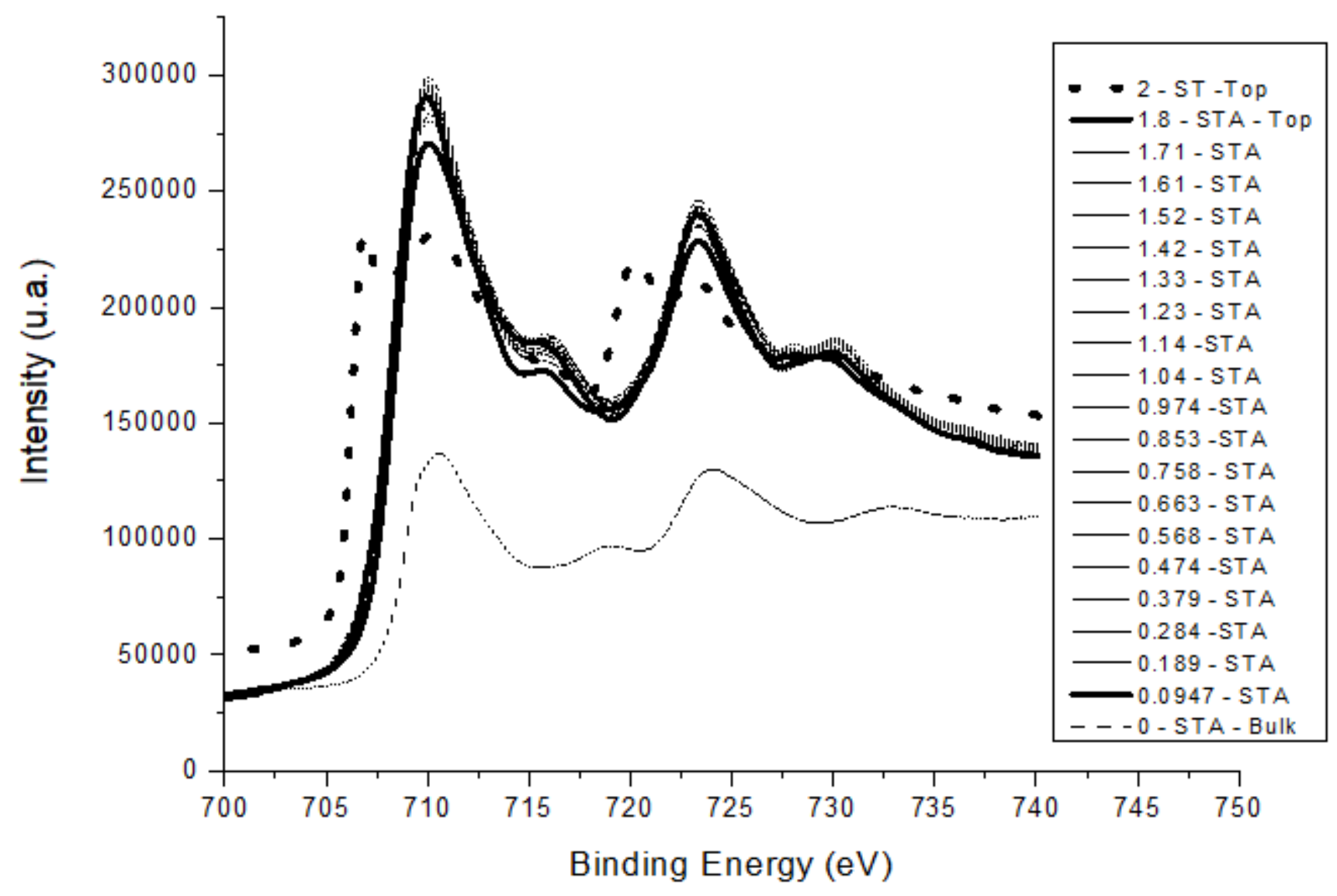

Figure 12

XPS Fe-2p peaks for the ST sample surface (ST-Top) and for the STA sample surface (STA - Top), and obtained after sputtering at different depths till the bulk. 